\title{
Escola, relações de dominação e experiências emancipatórias: o caso do Colégio Municipal de Pescadores de Macaé.
}

\section{School, relations of domination and emancipatory experiences: The matter of the Municipal School of Fishermen in Macaé.}

\author{
Clarissa de Almeida Aguiar Ribeiro'; Marcelo de Abreu Maciel ${ }^{2}$ \\ ${ }^{1}$ Fisioterapeuta e graduanda em Psicologia na Universidade Federal Fluminense - Campus Rio das Ostras. Tem interesse no \\ estudo dos processos de aprendizagem, considerando o indivíduo e a sociedade e desenvolve pesquisas na área de psicologia \\ da educação. ORCID: 0000-0002-9316-0606 \\ 2 Psicólogo pela Universidade Federal da Bahia, Mestre em Educação pelo Programa de Pós-Graduação em Educação da \\ UFRJ e Doutor pelo Programa de Pós-Graduação em Psicologia Social da UERJ. É professor no Departamento de Psicologia \\ da Universidade Federal Fluminense - Campus Rio das Ostras. Email mdamaciel@gmail.com/ORCID 0000-0002-2791- \\ 0456
}

\section{Palavras-chave:}

Colégio de Pescadores. Educação crítica.

Escolarização no Brasil. Sujeito.
RESUMO: O presente artigo apresenta uma reflexão sobre a possibilidade do espaço escolar se tornar um lugar de cidadania, de formação crítica e dialógica com o mundo. Tomando como ponto de partida alguns aspectos da História da Educação no Brasil e sua marca colonizadora e disciplinar, o texto busca mostrar como a escola nos dias atuais, apesar de algumas mudanças, ainda se mantém dentro de uma proposta tecnicista, conteudista e pouco problematizadora, transformando professores e alunos em sujeitos disciplinados e respondentes a programas educacionais pouco criativos e limitadores em sua reflexão. Ao final, apresentamos a experiência do projeto no Colégio Municipal de Pescadores de Macaé, como uma forma de exemplificar o que chamamos de uma escola que pensa a vida e suas práticas.

\section{Keywords:}

Fishermen school in Macaé. Critical education. Schooling in Brazil. Subject.
ABSTRACT: This article presents reflections on the possibility of turning the school space into a place of citizenship, of critical formation and dialog with the world. Considering some aspects of the History of Education in Brazil and its colonizer and disciplinary tradition, the text seeks to show how the school today despite some changes, still remains within a shallow technician proposal in its contents, transforming teachers and students into disciplined subjects and responders to unrealistic and limiting educational programs. At the end, we present the experience of the project at the Municipal School of Fishermen in Macaé, as a way to show an example of a school that considers life and its practices. 


\section{INTRODUÇÃO}

A história de vida de cada indivíduo carrega um sentido próprio, uma significação atribuída por aquele que a experimentou. Durante seu crescimento, este indivíduo precisa ser ouvido, estimulado, respeitado para desenvolver-se em uma relação crítica com o mundo e consigo mesmo. Nesse processo de desenvolvimento, a escola torna-se um espaço de diálogo fundamental e quando ela perde a capacidade de acolhimento destes indivíduos em suas diferenças, o que pode ocorrer é um efeito inverso, ou seja, ser um local opressivo e limitador da trajetória de crianças, jovens e professores.

Se esta prática encobre e não dialoga com a história do sujeito e suas diversas formas de estar e perceber o mundo, produz-se um indivíduo, que passa a atuar em sociedade a partir das ideias que lhe foram apresentadas sem possibilidade de questionar e problematizar. Se a prática educacional encontra-se aliada a interesses que objetivam despolitizar este ato, no sentido de não produzir uma educação emancipatória, há um risco de que aprendizado e desenvolvimento fiquem atrelados um entendimento alienado, que não possibilite desenvolver o recurso de auto conhecimento, de um olhar crítico na descoberta do mundo ao redor (FREIRE, 2013).

Ao analisarmos o percurso histórico do surgimento das escolas no Brasil, fica evidente, desde o seu início, a sujeição dos métodos de ensino aos interesses de estado, no sentido de manter a ordem social e favorecer a manutenção de certas relações de poder. Neste processo impositivo da educação, numa escala hierárquica que mantém acesa a relação de domínio e submissão, tanto alunos quanto professores ficam desprovidos da possibilidade de pensar suas práticas a partir de sua vivências. O sujeito deste sistema, então, está para além dos estabelecimentos escolares, sob o disfarce de um saber supremo que se apresenta acima das necessidades individuais e coletivas de cada região. O resultado é uma espécie de terceirização do ensino que não dialoga mais com a própria escola e o seu entorno.

Para romper com este padrão, é necessário, pois, repensar a escola e evitar a articulação desta com os interesses dominantes elaborando novas propostas que garantam à população a melhor qualidade de ensino possível (SAVIANI, 1999). Ao longo dos anos, nesta trajetória de implementação escolar, diversos grupos atuaram no sentido de romper com a educação tradicional e aplicar formas alternativas para o funcionamento deste processo. Alguns, mais evidentes, até hoje inspiram as técnicas de ensino adotadas nas escolas. Mas a 
reestruturação do ensino a partir de uma lógica mais reflexiva ainda é um desafio no Brasil. Em outros termos, o objetivo da educação de tornar um sujeito consciente de si e do mundo é suprimido por um modo de funcionamento muito mais calcado em um currículo nacional unificado e em avaliações com resultados numéricos e produtos mecanizados.

Ainda é visível a sujeição das metodologias de ensino a um padrão normatizado que restringe novas possibilidades de atuação popular no contexto escolar, limitando as contribuições dos próprios atores deste espaço: profissionais de ensino, pais e alunos. $\mathrm{O}$ aluno é encaminhado a seguir um padrão idealizado que aponta o seu sucesso ou o seu fracasso e aprende a atuar em sociedade conforme as normativas pré-estabelecidas, mas não torna-se capaz de enxergar seus próprios anseios, tampouco desenvolver uma percepção crítica que o proveja autonomia para traçar e alcançar seus objetivos.

Neste contexto, viemos mostrar a experiência narrada por professores e organizadores do Colégio Municipal de Pescadores de Macaé. Criada para resgatar a cultura da pesca artesanal associada ao currículo do ensino regular, esta escola de nível fundamental no município de Macaé, localizava-se em uma antiga região de pescadores altamente impactada pela atual economia petrolífera. A escola apresentava uma proposta diferenciada no currículo escolar que favorecia aos alunos e professores levantarem questões relacionadas ao aspecto socioambiental do entorno escolar e do próprio município (NEPOMUCENO; COSTA; LIANZA, 2015).

No entanto, por atuar em contra fluxo com os interesses da economia local, a escola enfrentava conflitos com a prefeitura, responsável pela manutenção financeira do estabelecimento. Que as escolas possam conduzir a função de educar como um papel social, configurando-se como um ponto de apoio e crescimento pessoal ainda hoje é um desafio encarado pelos educadores que buscam tornar este lugar menos impositivo e abrir novos caminhos.

\section{BREVE PANORAMA SOBRE A HISTÓRIA DA EDUCAÇÃO BRASILEIRA}

A trajetória da educação no Brasil é um campo de avanços e retrocessos quando pensamos nas reformas educacionais propostas e ocorridas nos diversos momentos de sua história. Em vários momentos, vários movimentos educacionais foram interrompidos antes de alcançar seus objetivos ou foram deslocados de seu real propósito, transformando-se em meros instrumentos de orientação técnica nas escolas, perdendo assim, toda a discussão política e transformadora que os embasava. 
O ambiente escolar, desta forma, vira apenas um espaço propício a ampliar o campo de atuação de tradições políticas e educacionais, com um viés disciplinar, no intuito de enquadrar os sujeitos, torná-los submissos, mecanizados e desprovidos de autonomia (FOUCAULT, 2014). Para Brandão (1981, p. 34), esta divergência pode ensinar, dentro de uma mesma metodologia, os homens a pensarem "uns como senhores, outros como escravos". Percebemos, então, que o funcionamento predominante ainda é o de produzir uma classe minoritária que tem acesso ao ensino de qualidade, ao desenvolvimento pessoal e formação que os prepara para desafios pedagógicos futuros.

Retomando, então, alguns aspectos desta história da educação brasileira, podemos perceber que esta intervenção ocorre desde o período colonial, quando a cultura portuguesa foi imposta aos nativos sob a forma de uma escola de jesuítas, fundada por membros da Companhia de Jesus e marcada pela catequização dos povos indígenas. Tratou-se de garantir tanto quanto possível que os nativos fossem inseridos no contexto dos costumes da colônia. Da mesma forma, os jesuítas administravam as primeiras escolas no Brasil, voltadas para uma elite colonial, afim de reproduzir neste país os princípios e as leis portuguesas (SAVIANI, 2005).

Assim, a escola que foi sendo desenvolvida desde a colonização do Brasil, seguia os princípios e os interesses europeus e desconsiderava os costumes e tradições dos povos que aqui já viviam. Fato, aliás, que irá marcar nossa vida escolar brasileira, principalmente no campo curricular. Com uma grande população formada por índios, negros, mestiços e imigrantes de toda parte do mundo, havia um longo trabalho a ser feito para ordenar toda a população em busca de um objetivo comum: captar força de mão de obra para o desenvolvimento da colônia, indiferente às crenças e habilidades próprias de cada grupo. $\mathrm{O}$ modelo de sociedade imposto seguia os padrões da própria sociedade portuguesa, ainda que o cenário social brasileiro, marcado pela miscigenação de povos e culturas diversos, fosse totalmente diferente das terras colonizadoras (PAIVA, 2016). Desta forma, é a partir dos valores colonialistas, pautados em costumes europeus que se inicia a educação escolar deste país.

Mais adiante, no início do século XIX, com a chegada da corte Portuguesa há uma modificação no cenário social. Os hábitos de vida da família real e a nobreza, inspirada nos costumes europeus, intensificaram na população o desejo de viver em uma sociedade sofisticada e educar seus filhos para que tenham uma posição social elevada no círculo aristocrático. Ao mesmo tempo, a modernização das cidades demandava serviços que exigiam mão de obra especializada. Nesta ocasião, a população era de maioria analfabeta, logo, a educação cultural e profissionalizante era vista como uma solução para resolver aquilo que era considerado um atraso social. (VILLELA, 2016) 
Assim sendo, para garantir que a sociedade em geral acatasse a autoridade da coroa, surge a ideia de expandir a instrução a todas as classes sociais, como forma de "avançar a civilização" e com a intenção oculta de unificar padrões sociais e difundir uma "moral universal". Foram criados os primeiros cursos de ensino superior no país e o ensino elementar tornou-se institucionalizado. Neste novo contexto, a especialização profissional ganhou destaque, enquanto os trabalhos manuais e artesanais eram relegados aos escravos e camponeses, considerados de menor importância. O aprendizado, antes realizado de forma livre, no próprio ambiente domiciliar, foi transferido para os estabelecimentos escolares. (VILLELA, 2016, p: 98)

A partir de então, as famílias deixam a cargo da escola não só o aprendizado das letras e das equações matemáticas, mas também dos valores sociais, morais, da herança cultural e até mesmo religiosa. O professor é a figura que detém a razão e conduz a transmissão do saber. (VILLELA, 2016) Desse modo, os princípios e normas aprendidos deixam de possuir uma herança ou código familiar e passam a ser instituídos por determinações escolares, que por sua vez são submetidas ao jugo estatal. Neste momento, percebemos que educar e escolarizar tornam-se concepções culturalmente associadas. A escola passa a ser o lugar de educar e o professor, o representante do conhecimento.

Esta ruptura com as tradições familiares proporcionada pela escolarização faz-se conveniente para uma nova forma de Estado, permitindo a inserção de novos valores sociais por meio de práticas de ensino, a cada vez que torna-se necessária uma mudança social coletiva. Deste modo, ao longo dos anos, para adequar a metodologia de ensino de forma que esta seja produtiva e alinhada às mudanças geradas pelo desenvolvimento industrial e pela introdução de um sistema capitalista, ocorrem diversas reformas educacionais, muitas inspiradas em técnicas pedagógicas desenvolvidas no exterior, para que o sistema de educação seja institucionalizado e uniforme em todo o país, filiando-se aos ideais de expansão econômica e modernização (CARVALHO, 2016).

Durante a ditadura civil militar, houve uma reestruturação de todos os níveis de ensino no país, incluindo os ramos acadêmico e profissional. Silva (2006), ao descrever este período aponta como o desenvolvimento do país era alinhado ao capital norte-americano e como foram imperativas as intervenções pedagógicas norte americanas. "Essas reformas acabaram com os movimentos de alfabetização baseados no método crítico desenvolvido por Paulo Freire, no qual a educação aparecia como "prática da liberdade'1", Isso interrompe a possibilidade de pensarmos um projeto problematizador de educação de forma regionalizada. A restrição do emprego da proposta freireana em território brasileiro, seguida da importação 
de novas técnicas de ensino repete o hábito costumeiro de menosprezar e descartar obras e pensadores de origem nacional e exaltar os ideais provenientes do exterior, especialmente de potências colonizadoras.

Pode-se constatar, portanto, que a influência de culturas estrangeiras nas escolas brasileiras é recorrente, e por este motivo, perdem-se as evidências da nossa história, a que é contada e experimentada pelo nosso povo. As transferências de conhecimento, antes passadas de uma geração a outra, num potencial de agir e viver em uma comunidade local e decifrar suas codificações passam agora aos domínios de um poder colonizador. Perde-se o contato com o território, com as experiências ancestrais e com as formas tradicionais de utilização dos recursos que a terra oferece. Mais que isso, as relações, com suas características e simbologias se desfazem, reduzindo a possibilidade de diálogos e discussões ideológicas que permitiriam agir em prol de interesses populares.

Dessa maneira, os interesses dominantes apropriam-se da educação de um povo, de todo um país e se fortalecem. Recentemente, Roberto Leher, professor da UFRJ citou em entrevista à revista Brasil de Fato, o caso de programas de ensino geridos por grandes grupos econômicos que projetam as normas do ensino fundamental:

Os setores dominantes se organizaram para definirem como as crianças e jovens brasileiros serão formados. E fazem isso como uma política de classe, atuam como classe que tem objetivos claros, um projeto, concepções claras de formação, de modo a converter o conjunto das crianças e dos jovens em capital humano (LEHER, 2015).

Portanto, constatamos que a lógica que orienta a escola atual mostra-se aliada ao poder econômico, que direciona os programas escolares e prepara sujeitos para serem colaboradores ativos à lógica produtiva de hoje. As iniciativas econômicas de origem pública e privada estão fortemente ligadas ao Estado. Este mesmo que é o norteador das políticas de educação no país e que, assim sendo, abraça os métodos que lhe convém. Nas palavras de Saviani (1999, p. 85), a pedagogia empregada nesta situação é justamente aquela que coloca "a educação a serviço da referida transformação das relações de produção".

Para Brandão, (1981, p. 33), "acontece com a educação o que acontece com todas as outras práticas sociais(...) sobre as quais um dia surge um interesse político de controle" que vão sendo gradualmente controladas por grupos específicos ditos especialistas, "mediadores entre o poder e o saber". Assim, o exercício de ensinar e aprender, um processo para transmitir habilidades e acordos comunitários construídos historicamente, vai sendo substituído por um novo modelo de educação que aponta outras verdades descoladas das necessidades locais, que irá formar uma nova geração.

No entanto, neste processo de renovação das coisas, o que ocorre é uma ruptura abrupta com o que já havia, com a cultura e as práticas antecedentes de transmissão de conhecimento. Já não se aplicam os saberes à utilidade coletiva. A educação que passa a ser 
transmitida unicamente nas escolas e que obedece a teorias alheias ao meio que ali se apresenta, deixa de ter o cunho instrutivo contextual e passa a agir a serviço de interesses peculiares, atuando muito mais de forma normatizadora do que edificadora (BRANDÃO, 1981).

A construção dos processos educativos no Brasil, em grande parte ainda ocorre de forma totalitária e hierarquizada, permitindo pouco ou nenhum envolvimento da comunidade local, dos alunos e familiares, tornando o ambiente escolar desinteressante e pouco motivador. Como reflexo, prevalece um sistema educacional que sustenta, até os dias de hoje, principalmente nas séries intermediárias como o fundamental, excessivamente conteudista, práticas de ensino que conservam metodologias pedagógicas incoerentes e conteúdos descontextualizados.

As unidades escolares que resistem a esta influência e conseguem adequar a sua realidade a uma aplicação didática que faça sentido e traga bons resultados a todos ainda são minoria. Vale lembrar que, muitas escolas que conseguiram fazer uma passagem qualitativa de suas práticas, passaram por uma reflexão de seu cotidiano escolar e se aproximaram de suas comunidades abrindo a escola para o que estava fora dela. Assim sendo, faz-se necessário repensar as propostas pedagógicas de forma que a escola possa retomar o diálogo com o que há de fundamental no mundo contemporâneo.

Analisando os dados mencionados acima, perguntamo-nos então por quem e para quem a escola vem sendo planejada? Tal planejamento deveria considerar a realidade social e cultural local afim de desenvolver atividades que pudessem favorecer o desenvolvimento individual e coletivo dos sujeitos envolvidos no processo de aprendizado. Considerando-se que os maiores envolvidos nas atividades realizadas no âmbito escolar são os professores e os alunos, seria natural que estes pudessem participar dos programas pedagógicos, evitando assim uma proposta vazia, desconexa do seu tempo e distante das realidades locais onde esta se aplica (SAVIANI, 1999).

\section{A ESCOLA QUE REPRODUZ SUJEITOS SUBORDINADOS À ECONOMIA ATUAL}

Como resultado da nossa história, somos um povo formado a partir de um ciclo colonizador, atravessado por multiculturas, por práticas diferenciadas que transmitem uma lucidez imensa, porém desvalorizada. Ainda que sejamos produtivos, em terra em que se plantando tudo dá, hoje dependemos enormemente da indústria alimentícia. Embora tenhamos uma das maiores biodiversidades do planeta, os nossos medicamentos são invariavelmente 
adquiridos em farmácias encontradas em cada esquina, desde os grandes centros às pequenas cidades de interior.

O mesmo aspecto subordinado vem se manifestando na forma de se vestir, na musicalidade, nas tradições folclóricas e mesmo na religiosidade. As percepções instintivas e as práticas comunitárias perdem-se com o tempo e confundem-se com uma demanda criada à parte das reais necessidades individuais e coletivas. Ao longo da história da educação, pudemos notar que a transmissão de conhecimento foi migrando do ambiente doméstico para instituições escolares. Quando o estado assume o controle da elaboração e do funcionamento de um modelo escolar padronizado com abrangência nacional, a escolarização vem facilitar a expansão do processo de alienação do homem em relação a si e a sua comunidade. (FREIRE, 2013)

Para Arendt (2005), esta relação entre a educação e a formação de uma nova ordem política está perigosamente associada, justamente por possibilitar o doutrinamento sem o uso da força. Os métodos de ensino empregados atualmente não cumprem seu papel essencial, mediador entre o sujeito e suas tradições familiares, mas produz uma sociedade regida pela lógica do trabalho apresentando um programa atraente e promissor, que gera a ilusão de proporcionar a todos a oportunidade de uma vida melhor. A respeito destas considerações, para Arendt (2005), citada em Cesar e Duarte (2010, p. 826), "vivemos numa 'sociedade de massas' que prioriza as atividades do trabalho e do consumo; que deseja avidamente a novidade pela novidade, orientando-se apenas pelo futuro imediato; e que nada quer conservar do passado".

O espaço escolar torna-se portanto um ambiente facilitador para que o Estado e todo seu sistema operante, ao se apropriar dos métodos de ensino empregados nas escolas, possa realizar uma adequação social. Assim, os projetos educacionais adaptaram-se a cada período histórico no sentido de atender aos interesses políticos e dominantes. Observando o cenário atual, as metodologias modernas são propensas a orientar de forma pragmática o desenvolvimento das aptidões individuais, ou seja, ao que interessa em termos de produtividade. Para Arendt (2005), esta proposta tende a reduzir as instituições de ensino em instituições meramente profissionalizantes.

Freire (2013) também menciona este papel disciplinador ao apresentar o conceito do que ele denomina "educação bancária", que aponta um aspecto fragmentador na educação, que resulta em uma dicotomia entre o mundo e o homem, na intenção de adaptar este àquele, de forma que os alunos não desenvolvam o hábito de uma interpretação própria, mas aprendam e repitam o modo de funcionamento do mundo que lhes é apresentado. Dentro desse contexto, "cabe à educação apassivá-los mais ainda e adaptá-los ao mundo" (FREIRE, 2013, p.88). 
Adentrando o ambiente escolar, a disciplina tornou-se pois 'elegante', abolindo as relações de dominação brutas e violentas e dando passagem a uma forma sutil de dominar e esculpir o indivíduo, que o torna tanto mais capacitado quanto mais adaptado, conformado, obediente. Afinal, repressão e constrangimento tornaram-se termos condenados nas instituições educacionais e já se foram os tempos de escravidão e da domesticidade. Pouco a pouco, a dominação bruta e violenta foi sendo substituída por um novo processo disciplinar que conquistava adeptos dispostos a seguir padrões de comportamento, desenvolver certas habilidades e ocultar outras tantas, porque em si lhes tinham imposto um novo sentido para a vida. (FOUCAULT, 2014).

Aos professores foi determinado como e o que ensinar, não pela sua importância histórica ou comunitária, mas por uma lógica conteudista, que propõe-se a cumprir um cronograma em um tempo específico, garantindo que tudo que seja necessário à sobrevivência intelectual dos educandos tenha sido exposto. Para Arendt (2005), os professores passam a se especializar em métodos pedagógicos que primam pela excelência de ensino, mas perdem uma compreensão mais abrangente do conteúdo que é ensinado.

Muitos dos profissionais que trabalham em instituições disciplinares já foram subjugados a este esquema que os leva a crer que estão atuando dentro de padrões inovadores e modernos e, no entanto, seguem aplicando as mesmas técnicas encobertas em novas couraças. Já perderam sua capacidade de análise crítica e não se percebem eles mesmos como os próprios "corpos dóceis" (FOUCAULT, 2014). Estes sujeitos foram disciplinados para disciplinar.

Assim sendo, a educação parece perder o aspecto libertador e criador e torna-se um instrumento de controle. A dissociação do homem com o seu próprio espaço social é, desta forma, maléfica, pois compreende um viés centralizador de ensino e uma imposição do saber que frequentemente não permite uma continuidade das sabedorias ancestrais e tampouco um ensinar-aprender compartilhado. A respeito disso, Brandão (1981) menciona:

\footnotetext{
... a educação do colonizador, que contém o saber de seu modo de vida e ajuda a confirmar a aparente legalidade de seus atos de domínio, na verdade não serve para ser a educação do colonizado. Não serve e existe contra uma educação que ele, não obstante dominado, também possui como um dos seus recursos, em seu mundo, dentro de sua cultura (BRANDÃO, 1981, p. 11).
}

Para o autor, o processo de ensinar-aprender que caracteriza uma construção social, configura uma transferência de ideias entre os homens que mantém a ordem das coisas, permite a preservação da existência e a transmissão de saberes às próximas gerações. Assim, a educação seria uma troca em sociedade que "continua no homem o trabalho da natureza de fazê-lo evoluir, de torná-lo mais humano" (BRANDÃO, 1981, p. 14). No entanto, o que vem 
acontecendo é uma colonização dos próprios métodos de ensino e uma consequente apropriação do modo de se pensar o mundo que desconstrói as tradições e os laços sociais.

As experiências comunitárias adquiridas ao longo das gerações perdem seu valor; vale mais o estudo técnico ou científico; conteúdos que compõem a base curricular do ensino, voltados para uma lógica e projetados a partir de uma metodologia que na maior parte das vezes não se relaciona com a realidade vivida pelo aluno. E, se afinal se este indivíduo não se adequa a esta sistematização do ensino, ele retoma o seu lugar de origem mas desconhece as técnicas elementares para sua subsistência naquela antigo modo de vida.

Reconhecemos, sim, a importância do acesso a instruções específicas que possibilitem ao sujeito refletir sobre e encontrar sua função na economia vigente. O problema encontra-se na maneira como os aspectos da formação escolar de um indivíduo são determinados, independente de sua realidade e de seus interesses próprios. Nesta circunstância, os alunos deverão mostrar-se perfeitamente adaptados às exigências da escola, apresentar boas notas e comportar-se de forma conveniente, sob o risco de, ao apresentarem desvios desta régua, serem considerados inaptos para o êxito profissional e até mesmo pessoal.

Sabendo que as normas sociais vigentes seguem um padrão dominante e se valem de artimanhas tão bem elaboradas e ainda, que o mundo, em constante processo de globalização acata estas normas cada vez mais e mais, o sujeito crítico se vê sozinho diante de uma entidade fortalecida e sente-se enfraquecido para seguir com novas ideias ou simplesmente questionar as colocações impostas à sua frente.

\section{A VERTICALIZAÇÃO NAS ESCOLAS: UM PROBLEMA NAS PRÁTICAS DE ENSINO}

Este modelo escolar que resultou como predominante no Brasil vem servindo como um instrumento de controle em massa que reforça relações de poder e dependência e impacta tanto as classes mais pobres quanto as ricas. Mais que isso, tornou-se ainda um bem de consumo, o qual quanto mais se tem, mais condições terá para disputar uma vaga no acirrado campo de trabalho do mundo atual. As mesmas estratégias de educação, embora desenhem caminhos diferentes em cada classe social, ainda assim, mantêm o enredo político já existente, sem que seja ampliada uma consciência social que permitisse a todos o direito de decidir que rumo gostariam de trilhar. Trata-se de sustentar um alheamento popular que é capaz de manter grande parte da população afastada do controle político e de um engajamento social. Desta forma, não há abertura para a possibilidade de participação consciente para uma verdadeira forma de democracia. 
Os reflexos da influência histórica na formação da escola nos séculos passados permanecem até os dias atuais. A sociedade, no entanto já é outra. A população, o entorno, tudo é um outro. Mas as mudanças ainda são lentas e sofrem repressão devido ao conflito de interesses entre dominantes e dominados. É necessário pensar na possibilidade de articular a realidade em que vivemos a novas formas de educar, possibilitando a transposição das questões sociais.

Ao elaborar o modo de funcionamento da escola, é preciso pois, que se tenha a prudência de observar se os métodos pedagógicos desenvolvidos para um outro momento histórico, ou para uma outra região, produziriam efeitos genuinamente positivos para a população de uma outra escola, em outro momento ou em outra região. É preciso ter a delicadeza de não deseducar toda uma geração de alunos com propostas pedagógicas préfabricadas incutidas em uma comunidade que já possui seus próprios meios eficazes de transmissão de saber (BRANDÃO, 1981). A programação do conteúdo pedagógico deve, pois, contemplar uma interação com a população e o entorno o qual aquela unidade escolar acolhe.

Por conta destes fatores - região, período histórico e população a que atende - cada escola é única e contém suas especificidades. Logo, os conteúdos e metodologias pedagógicas também deveriam levar em conta as necessidades e os interesses de cada escola. Para Saviani (1999), todos os elementos que ali se implicam, os professores, os alunos, a transmissão e a aquisição de conhecimento, devem ser considerados de modo que o processo de aprendizagem possa resultar em ação, proporcionando uma consciência que venha a promover participação social e resolução de problemas encontrados dentro de sua realidade.

Quando a comunidade tem a oportunidade de participar de um processo de criação, o resultado torna-se mais consistente. Com a ajuda de todos, é possível elaborar um espaço de troca de vivências, de formação de indivíduos conscientes a partir de sua própria capacidade de crítica. "Quanto mais assumam os homens uma postura ativa na investigação de sua temática, tanto mais aprofundam a sua tomada de consciência em torno da realidade e, explicitando sua temática significativa, se apropriam dela" (FREIRE, 2013, p. 137).

Para Freire, não basta ouvir a comunidade, os alunos e pais de alunos a respeito de novas propostas para o funcionamento de uma escola. Trata-se sim, de deixar de lado as idealizações preconcebidas, despir-se de uma verdade inculcada ao longo da história em teorias abstratas ou práticas distantes, sair de uma posição de superioridade com relação ao outro e abrir-se ao diálogo. Estamos falando de humanizar as práticas de ensino, se permitir um encontro entre educadores e alunos, pais e pedagogos.

Os idealizadores que venham propor novas formas de ensino nas escolas esbarram constantemente nas barreiras impostas pelo estado, por valores morais ditados pelos interesses 
dominantes. Em A Educação Libertária, Lourau (1997) menciona grupos de pessoas na Europa que, ao longo da história, implementavam suas ideologias através de movimentos que buscavam revolucionar o sistema educacional vigente. Contudo, a repressão e resistência estatista eram constantes e invasivas. O espaço escolar, os métodos de educação e a instrução científica aplicados já eram regulados por interesses puramente políticos e econômicos. No Brasil a história se repete quando observamos um esvaziamento de propostas que foram interrompidas ou aproveitados para outros fins.

Ao longo do tempo, indivíduos e grupos com ideias inovadoras não se cansam de tentar novas formas de educação - a educação que liberta. Dentre inúmeras experiências, algumas mais bem sucedidas, outras menos, na Alemanha, a denominada "Escola de Hamburgo", abrangeu diversas escolas primárias, eliminando programas e disciplinas rígidas e funcionou a partir de conceitos criados como pequenos grupos atuantes e centros de interesse. Esta experiência crítica tornou-se possível pois estavam implicados os pais e professores. Ambos sentiam-se pertencentes e atuantes na instituição de ensino em que estavam envolvidos, foram capazes de fazer uma análise geral e crítica, trabalhar em coletivo e aplicar a mudança (LOURAU, 1997).

Também no Brasil, em diferentes momentos tivemos ativistas e representantes de novas propostas, buscando solucionar, com a implementação de um nova perspectiva sobre a educação nacional, as profundas desigualdades sociais que marcaram nosso país desde sempre. Podemos falar da proposta da Escola Nova, movimento liderado no início da década de 30 por um grupo de educadores que apresentavam planos de uma nova forma de educação que permitisse um crescimento igualitário no país. Seria a oportunidade de formar uma sociedade capaz de gerir em sã consciência o seu entorno comunitário, preparando alunos que pudessem, não somente desenvolver a economia do Brasil, mas ser parte integrante de uma nação dotada de autonomia, menos desigual e mais crítica.

Este movimento teve consequências positivas, como a possibilidade de expandir o ensino público, na intenção de que o ambiente escolar fosse para todos o abrir de portas, a oportunidade e a igualdade. Esta ação encontrou resistência na ordem de ensino religioso, então predominante no país. Alguns anos depois, ao ganhar força e avançar no campo da educação, os princípios da Escola Nova foram finalmente abraçados pela pedagogia cristã. Para Saviani (2005), essa fusão promoveu um período de "intensa experimentação educativa", renovando o campo da pedagogia no Brasil. "Foram organizados cursos pilotos que valorizavam os interesses, a iniciativa e as atividades dos alunos, desenvolviam o método de projetos, o ensino centrado em núcleos temáticos extraídos das preocupações político existenciais dos estudantes (...)" (SAVIANI, 2005, p.18).

Contudo, o autor aponta o enfraquecimento desta proposta, no final da década de 60 , a 
partir da extinção do Centro Brasileiro de Pesquisas Educacionais. Com o golpe de 64, os militares assumem o poder e o ensino no país assume um modelo de educação produtivista associado aos interesses econômicos, que Saviani denomina "concepção produtivista" de educação (SAVIANI, 2005, p. 21). O ensino para todos, uma proposta tão relevante, é mais uma vez ameaçado de apresentar-se sob interesses suspeitos que classificam e excluem.

Mencionando o trabalho de grupos inovadores, com projetos significativos, gostaria de fazer uma referência à história de uma extinta escola de ensino fundamental localizada no município de Macaé - o Colégio Municipal de Pescadores, como forma de exemplificar o caso, ainda que breve, da possibilidade de políticas públicas e interesses sociais atuarem em conjunto, apresentando resultados positivos.

\section{COLÉGIO MUNICIPAL DE PESCADORES DE MACAÉ}

Ao observar, a partir de revisão bibliográfica, as diversas tentativas de novas propostas em educação ao longo dos anos, recorreu-me a lembrança deste estabelecimento e um artigo publicado em 2015 por ex-professores da escola. O Colégio Municipal de Pescadores ${ }^{2}$, localizado na cidade litorânea de Macaé, no Estado do Rio de Janeiro, foi fundado em 2003, parceria da prefeitura do referido município com a UFRJ, diferenciando-se das demais escolas por apresentar uma proposta pedagógica que valorizava a cultura regional de pesca artesanal e formação crítica em educação ambiental, marcando a estreita associação entre natureza e sociedade. Em uma cidade que passou a exercer uma atividade predominantemente petrolífera e recebeu o título de Capital Nacional do Petróleo, como não dizer que seus ideais confrontavam com a intenção da economia vigente e dominante?

No artigo Uma experiência de pedagogia orientada por projetos no Colégio Municipal de Pescadores de Macaé, Nepomuceno, Costa e Lianza (2015) contam que todos funcionários, alunos, pais - estavam positivamente implicados no desenvolvimento do projeto. Segundo os autores, alguns professores residiam no bairro da escola, o que permitia ainda uma troca de saberes "não formal" e um vínculo amistoso entre os docentes, os alunos e a comunidade ao redor. Além disso, a parceria da universidade com a prefeitura possibilitou ampliar a percepção sobre a realidade local e inspirou a construção de mais escolas municipais que ofereciam horário integral. "Somente através de um constante diálogo entre diversos professores do colégio, direção, coordenadores de área e a comunidade escolar conseguimos inovar no processo de ensino-aprendizagem" (NEPOMUCENO; COSTA; LIANZA, 2015, p. 144).

${ }^{2}$ https://www.youtube.com/watch?v=WJicMOgEfpU 
O colégio funcionava em horário integral, com uma pedagogia orientada por projetos, permitindo um currículo ampliado que oferecia as disciplinas comuns ao ensino fundamental pela manhã e um adicional de oficinas no período da tarde, que estariam relacionadas ao estudo, manejo e produção da pesca artesanal, praticada ainda por muitos pais e familiares de alunos. Dentre as disciplinas oferecidas pelo projeto, constavam ainda as ditas "profissionalizantes" de Construção Naval, Navegação e Natação, Comunicação Social, Artes e RSA - Relações Socioambientais, esta última ligada aos aspectos sociais e de meio ambiente da região no entorno da escola (NEPOMUCENO; COSTA; LIANZA, 2015). Na escola, localizada praticamente na areia da praia, ao lado do mar, o conceito de sala de aula era subjetivo, podendo migrar dos cômodos abafados com carteiras envelhecidas para um barco em alto-mar, uma praça, uma lagoa, dentre outros pontos inusitados. Devido à carga horária ampliada, a escola oferecia café da manhã, almoço e lanche da tarde (NEPOMUCENO; COSTA; LIANZA, 2015).

As atividades incluíam estudos em matemática, ciências, história, como a escola tradicional. Mas estes conhecimentos incorporavam-se aos projetos que vivenciavam as práticas e a cultura local, exaltavam os entendimentos populares e as necessidades próprias dos alunos - a dança, a poesia, o surfe e a brincadeira livre (NEPOMUCENO; COSTA; LIANZA, 2015). Assim, ao final do ensino fundamental, o aluno estaria apto a praticar a atividade pesqueira, se assim desejasse, mas também estaria qualificado para prosseguir os estudos tradicionais do ensino médio e universitário. E mais que isso, independente de sua escolha, o aluno estaria consciente das tradições da comunidade local, a qual estaria provavelmente relacionada à história de vida de seus próprios familiares (NEPOMUCENO; COSTA; LIANZA, 2015).

O diálogo ali estabelecido entre os diretores, professores, alunos e comunidade abria uma liberdade de ação para além de uma grade curricular unificada e de um cronograma estático. Na prática isso refletia a possibilidade de que os professores pudessem ensinar o que aprenderam no meio acadêmico e em suas vidas. Em contrapartida, era-lhes oferecido um contínuo de aprendizagem ao terem a chance de conceber uma nova forma de ensino que permitia um encontro menos hierarquizado e mais humano.

No entanto, por falta de recursos e de apoio, devido a atritos entre a prefeitura e a universidade, as portas do colégio foram fechadas em 2010. Esta dificuldade enfrentada por metodologias alternativas ao padrão pedagógico vigente já havia sido presumida anteriormente por Lourau (1997) como uma tendência mundial no funcionamento das escolas. "A diferença cultural das duas instituições, em pouco tempo, gerou conflitos de diversas naturezas: sobre o modo como os professores deviam ser geridos, sobre as práticas pedagógicas, as formas de cobrança dos resultados, entre outros pontos" (NEPOMUCENO; 
Ensino, Saúde e Ambiente - Número Especial, pp. 371-388, Junho. 2020

COSTA; LIANZA, 2015; p. 147). Com o artigo, os autores demonstram o relato de uma experiência não como uma ideia a ser repetida, mas como forma de expor a validade de uma experiência a partir de uma proposta diferenciada em ensino, que permite a abertura de novas práticas pedagógicas e um maior entrosamento entre o estabelecimento de ensino e a comunidade local.

ESTEVES e BOZELLI (2018), relatam que a escola surgiu com a proposta de agregar os conhecimentos acadêmicos aos populares. Porém, as atividades da escola foram encerradas pela prefeitura do município, que alegou não ter condições de continuar financiando o alto custo do projeto. Os autores consideram esta interrupção uma perda para a sociedade, que não estaria "preparada para um projeto desta abrangência e magnitude social". Atualmente, com o evidente declínio da economia petrolífera, este projeto seria uma forma de resgatar e manter a atividade pesqueira local, uma das bases da economia do município de Macaé (ESTEVES e BOZELLI, 2018, p. 134).

E com o fim deste e de tantos outros projetos, perguntamo-nos o que ficou desta experiência? Podemos afirmar que tenham sido inúteis ou fracassadas? Pelo relato no artigo citado acima, percebemos que teria sido um troca de experiências riquíssima para jovens professores recém-formados, alunos de pós-graduação e professores já atuantes nas escolas do município. Alguns seguiram carreira acadêmica e são agora professores universitários e mantêm esta prática viva em suas novas relações de trabalho. Em termos práticos, o colégio levou a classificação de terceiro lugar como melhor escola do município, avaliada pelo Ideb em $2007^{3}$.

Os alunos também foram beneficiados, tendo vivido tantas experiências diferentes e se destacando, muitos deles, já na fase adulta em profissões variadas. Há, inclusive, registros de alunos que ingressaram para cursar o nível superior no mesmo Campus da UFRJ, que na ocasião atuou em parceria com a escola e estão hoje, eles mesmos, se formando professores. Recordando Guattari (1981), se na fase adulta, eles decidem pelos apelos da sociedade dominante, que façam conscientes de suas escolhas, que sejam capazes de observar e compreender a si mesmos. Para os autores do artigo, “(...) o contato com as diferentes práticas pedagógicas ampliou as possibilidades de se reinventar e traçar seus rumos em uma sociedade calcada no consumo e em processos fortes de individualização" (NEPOMUCENO; COSTA; LIANZA, 2015). Seria este o início de uma caminhada rumo à liberdade?

${ }^{3}$ http://www.macae.rj.gov.br/noticias/leitura/noticia/escolas-de-macae-sao-destaque-no-ideb 
Ensino, Saúde e Ambiente - Número Especial, pp. 371-388, Junho. 2020

\section{CONSIDERAÇÕES FINAIS}

Podemos perceber, portanto, que, desde a implementação das escolas no Brasil, este processo ocorreu sob os olhares do Estado, com uma orientação disciplinar, que configura um encontro com a ideia de controle das massas pelo Estado (FOUCAULT, 1979). O resultado é um padrão escolar nacional unificado, que funciona de forma profundamente desigual entre as classes sociais. Predominantemente voltado para formação profissional de indivíduos aptos a atender às necessidades de produção econômica no país, este padrão tende a valorizar conteúdos tecnicistas e artificiosos, pouco voltados para o desenvolvimento crítico do sujeito.

Sob tais circunstâncias, é importante promover um movimento comprometido com a escola no intuito de manter acesa a chama da educação em seu potencial crítico e libertador. É evidente o momento delicado em que se encontra a situação da educação no Brasil. Para Arendt (2005), um momento de crise seria oportuno para impelir a reflexão sobre o processo de ensinar, firmado no compromisso de mostrar como o mundo é e deixar que as mudanças aconteçam como um movimento natural, que não segue fluxos ou modismos.

O importante, ao se conceber um plano de mudanças é que não pensemos na mudança apenas pela mudança. Não se trata de abandonar o velho e trazer o novo na proposta de modernizar as técnicas adotadas num sistema nacional de educação, ou de lançar um olhar pessimista sobre o funcionamento das escolas. Mas é fundamental que à estas escolas, seja permitido continuar o trajeto da educação, com autonomia para traçar os seus próprios caminhos.

O caso do Colégio Municipal de Pescadores de Macaé é apenas um exemplo, dentre tantos outros projetos diferenciados em educação tocados nas inúmeras escolas do país e ilustra a dificuldade enfrentada para a sua continuidade e o consequente encerramento abrupto das atividades. Muitos destes projetos não chegam a ganhar visibilidade para além dos muros do próprio estabelecimento e contam apenas com a dedicação dos profissionais de ensino que, carregados de sensibilidade e uma percepção ampliada do mundo, conseguem ouvir as necessidades locais e elaborar práticas eficazes no processo de ensino e aprendizagem.

É visível, portanto, que a educação exerce um papel fundamental no desenvolvimento da sociedade e dos indivíduos. Todavia, é necessário que ela seja conduzida à parte de interesses dominantes e exclusivos, e permita que outras questões sejam levantadas. É essencial que este movimento seja direcionado para desenvolver a escola em todo o seu potencial, como um espaço de crescimento pessoal, de cunho libertador, um ponto de apoio que possibilite a promoção e o exercício da democracia. 
Ensino, Saúde e Ambiente - Número Especial, pp. 371-388, Junho. 2020

\section{REFERÊNCIAS}

Acervo Navegando na História da Educação Brasileira. Disponível em http://www.histedbr.fae.unicamp.br/navegando/index.html Acessado em 15 de fevereiro de 2016.

ARENDT, H. Entre o passado e o futuro. Tradução Mauro W. Barbosa. $5^{\text {a }}$ ed. São Paulo: Perspectiva, 2005.

BRANDÃO, C. R. O que é educação. São Paulo: Brasiliense, 1981.

CARVALHO, M. M. C. Reformas da Instrução pública in LOPES, E. M. T.; FARIA FILHO, L. M.; VEIGA, C. G. (orgs.): 500 anos de educação no Brasil. $5^{\mathrm{a}}$ ed. Belo Horizonte: Autêntica, 2016

CESAR, M. R.; DUARTE, A. Hannah Arendt: pensar a crise da educação no mundo contemporâneo. Educação e Pesquisa, São Paulo, v. 36, n. 3, p. 823-837, Dezembro, 2010. Disponível em http://www.scielo.br/scielo.php?script=sci_arttext\&pid=S151797022010000300012\&lng=en\&nrm=iso Acessado em Setembro, 2019. http://dx.doi.org/10.1590/S1517-97022010000300012

FOUCAULT, M. Microfísica do poder. Organização e tradução de Roberto Machado. $5^{\mathrm{a}}$ ed. Rio de Janeiro: Edições Graal, 1979.

FOUCAULT, M. Vigiar e Punir: Nascimento da prisão. Tradução de Raquel Ramalhete. 42a ed. Petrópolis, RJ: Vozes, 2014.

FREIRE, P. Pedagogia do Oprimido. 23ª ed. São Paulo: Paz e Terra, 1996.

GUATTARI, F. As creches e a iniciação. In: GUATTARI, F. Revolução molecular: pulsação política do desejo. $3^{\mathrm{a}}$ ed. São Paulo: Brasiliense, 1987.

LEHER, R. “Grandes grupos econômicos estão ditando a formação de crianças e jovens brasileiros". Entrevista concedida a Luiz Felipe Albuquerque. Revista Brasil de Fato, 2015. Disponível em: http://brasildefato.com.br/node/32359 Acessado em 13 de outubro de 2015.

LOURAU, R. A Educação Libertária. L’homme et la société, n. 123-124/1-2, p. 45-55. Tradução: Antonio Carlos Cerezzo e Heliana de Barros Conde Rodrigues. 1997.

NEPOMUCENO, V.; COSTA, R. N.; LIANZA, S. Uma experiência de pedagogia orientada por projetos no Colégio Municipal de Pescadores de Macaé in ADDOR, F.; LIANZA, S.(orgs.): Percursos na extensão universitária: Saindo da Torre de Marfim. $1^{\text {a }}$ ed. Rio de Janeiro: UFRJ, 2015

PAIVA, J. M. Educação Jesuítica no Brasil Colonial in LOPES, E. M. T.; FARIA FILHO, L. M.; VEIGA, C. G. (orgs.): 500 anos de educação no Brasil. $5^{\text {a }}$ ed. Belo Horizonte: Autêntica, 2016

SAVIANI, D. Escola e democracia: teorias da educação, curvatura da vara, onze teses sobre educação e política. 32a ed. São Paulo: Cortez/Autores Associados, 1999. 
SILVA, R. Notas para uma genealogia da Psicologia Social. Psicologia e Sociedade. 16(2). p. 12-19. 2004. Disponível em http://www.scielo.br/pdf/psoc/v16n2/a03v16n2.pdf Acessado em 18 de Setembro de 2019.

VILLELA, H. O mestre escola e a professora in LOPES, E. M. T.; FARIA FILHO, L. M.; VEIGA, C. G. (orgs.): 500 anos de educação no Brasil. $5^{\text {a }}$ ed. Belo Horizonte: Autêntica, 2016 